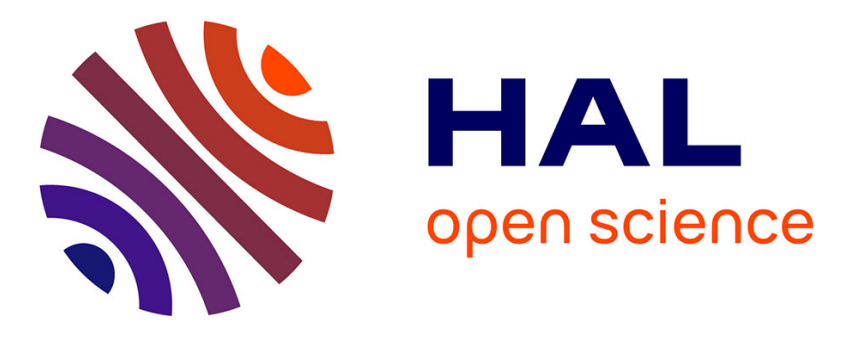

\title{
Enantioselective and Diastereodivergent Synthesis of Spiroindolenines via Chiral Phosphoric Acid-Catalyzed Cycloaddition
}

Thomas Varlet, Mateja Matišić, Elsa van Elslande, Luc Neuville, Vincent Gandon, Géraldine Masson

\section{To cite this version:}

Thomas Varlet, Mateja Matišić, Elsa van Elslande, Luc Neuville, Vincent Gandon, et al.. Enantioselective and Diastereodivergent Synthesis of Spiroindolenines via Chiral Phosphoric Acid-Catalyzed Cycloaddition. Journal of the American Chemical Society, 2021, 143 (30), pp.11611-11619. 10.1021/jacs.1c04648 . hal-03329179

\section{HAL Id: hal-03329179 https://hal.science/hal-03329179}

Submitted on 30 Aug 2021

HAL is a multi-disciplinary open access archive for the deposit and dissemination of scientific research documents, whether they are published or not. The documents may come from teaching and research institutions in France or abroad, or from public or private research centers.
L'archive ouverte pluridisciplinaire HAL, est destinée au dépôt et à la diffusion de documents scientifiques de niveau recherche, publiés ou non, émanant des établissements d'enseignement et de recherche français ou étrangers, des laboratoires publics ou privés. 


\title{
Enantioselective and Diastereo-divergent Synthesis of Spiro-indolenines via Chiral Phosphoric Acid-Catalyzed Cycloaddition
}

Thomas Varlet, ${ }^{\dagger}$ Mateja Matišić, ${ }^{\dagger}$ Elsa Van Elslande, ${ }^{\dagger}$ Luc Neuville, ${ }^{\dagger}$ Vincent Gandon, ${ }^{*, \neq, \neq}$ Géraldine Masson ${ }^{*+}$

\footnotetext{
' Institut de Chimie des Substances Naturelles, Université Paris-Saclay, ICSN-CNRS UPR 2301, France.

₹ Institut de Chimie Moléculaire et des Matériaux d'Orsay (ICMMO), 91405 Orsay, France; Laboratoire de Chimie Moléculaire (LCM), France.

¥ Laboratoire de Chimie Moléculaire (LCM), CNRS UMR 9168, École Polytechnique, Institut Polytechnique de Paris, route de Saclay, 91128 Palaiseau cedex, France.
}

\begin{abstract}
3-indolylmethanols with 1,3-dienecarbamates. Modular access to two different diastereoisomers with high enantioselectivities was obtained by careful choice of reaction conditions. Their functional group manipulation provides an efficient access to enantioenriched spirocyclohexyl-indolines and -oxindoles. The origins of this stereocontrol have been identified using DFT calculations, which reveal an unexpected mechanism compared to our previous work dealing with enecarbamates.
\end{abstract}

ABSTRACT: A diastereodivergent and enantioselective synthesis of chiral spirocyclohexyl-indolenines with four contiguous stereogenic centers is achieved by a chiral phosphoric acid catalyzed cycloaddition of 2-susbtituted

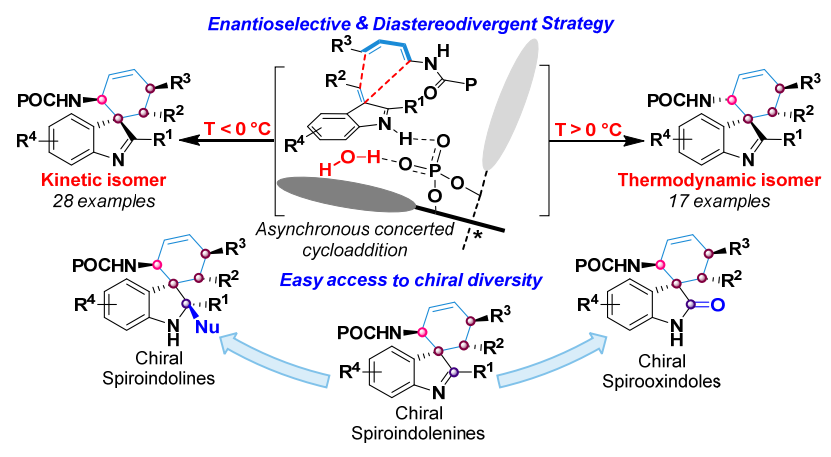

Chiral spiro indoles derived units are important structural motifs encountered in various naturally occurring alkaloids as well as biologically active compounds. ${ }^{i}$ They are key intermediates for the synthesis of numerous natural products.ii The development of direct and efficient catalytic methods for their enantioselective synthesis has therefore attracted the attention of synthetic organic chemists. A number of enantioselective methodologies have been successively reported over the years.iii However, in contrast to spirocyclohexyl-oxindoles, iv asymmetric strategies for building related indolines and indolenines are limited in number. ${ }^{v}$ In 2017, Gandon, Guinchard et al. ${ }^{5 a}$ reported an example of $\mathrm{Au}(\mathrm{I})$-catalyzed enantioselective cyclizations of $\mathrm{N}$-propargyl tryptamines, providing the corresponding spiroindolenines in moderate yield and enantioselectivity (up to $68 \% e e$ ). The same year, Zheng, You et $a{ }^{.5 b}$ developed an efficient method for synthesizing spirocyclohexyl-indolenines based on Ir-catalyzed asymmetric dearomatization of bis(indol-3-yl)allylic carbonates. One year later, the same group disclosed an enantioselective dearomatization of indolyl dihydropyridines using chiral phosphoric acid catalysis to afford various spiroindolines with high yields and enantioselectivities. ${ }^{5 c}$ More recently, Wei, Shi et al. developed an elegant enantioselective desymmetrization of bis(indol-3yl)-allenes catalyzed by a chiral Au complex, which afforded fused spirocyclohexyl derivatives with high enantioselectivities. ${ }^{5 \mathrm{~d}}$ Despite these achievements and while derivatives containing a heteroatom in the spirocyclohexyl ring were produced, catalytic asymmetric syntheses of all-spirocarbocyclic indoline derivatives have remained extremely scarce. To the best of our knowledge, only very recently Breit et al. achieved a stereoselective synthesis of unfused spirocarbocyclic indolenines though rhodiumcatalyzed cyclization of $\mathrm{N}$-allenyltryptamines and 3 -allenylindoles, delivering a moderate to high level of enantio- and diastereoselectivity (Scheme 1, a).${ }^{5 e}$ Indeed, the enantioselective construction of highly substituted spirocarbocycles with the control of multiple stereocenters, including the quaternary spirocenter, in a single assembly step from easily accessible starting materials remains a significant challenge. 
Scheme 1. Enantioselective catalytic synthesis of spirocyclohexyl-indolines and -indolenines

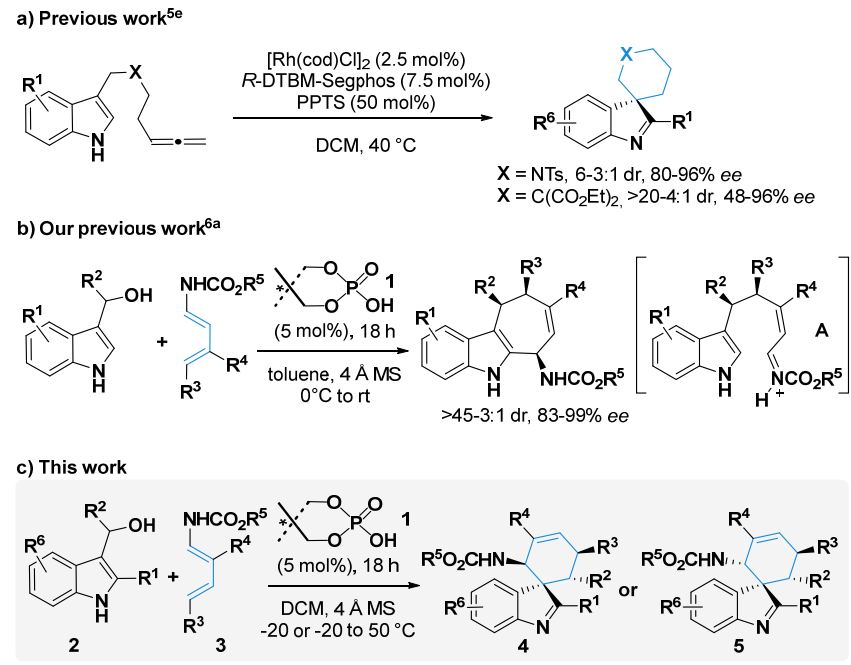

Recently, we disclosed an efficient enantioselective synthesis of cyclohepta[ $b]$ indoles involving a chiral phosphoric acid-catalyzed formal (4+3)-cycloaddition of 3-indolylmethanols with 1,3-dienecarbamates (Scheme 1, b). via,vii,viiiix Mechanistic investigations provided evidence for a two-step reaction process involving vinylogous addition of the diene to a vinyliminium ion ${ }^{\mathrm{x}}$ generated in situ from the 3indolylmethanol, followed by an intramolecular $\mathrm{C}_{2}$-indole alkylation of the resulting imine $\mathbf{A}$. Based on this, we reasoned that incorporation of a substituent at the $C_{2}$ position of the indole moiety may promote electrophilic substitution at $C_{3}$ rather than $C_{2}$ and may lead to an efficient synthesis of enantioenriched spirocarbocyclic indolenines. Herein we report a highly enantioselective synthesis of polysubstituted spirocyclohexyl-indolenines having up to four contiguous stereocontrolled chiral centers, including a quaternary one, in satisfying yields and with excellent enantio- and diastereoselectivity (Scheme 1, c). DFT computations and experimental studies provided a clear mechanistic picture of the transformation and revealed an unexpected activation mode by the chiral phosphoric acid catalyst.

Initially, (2-methyl-1H-indol-3-yl)(phenyl)methanol (2a) and benzyl (penta-1,3-dien-1-yl)carbamate (3a) were chosen as model substrates to evaluate our hypothesis (Table 1, entry 1). Pleasingly, performing the reaction at $0{ }^{\circ} \mathrm{C}$ with $(S)-\mathrm{H}_{8}$-BINOL-phosphoric acid catalyst 1a delivered the desired spirocyclohexyl-indolenines $\mathbf{4 a}$ and $\mathbf{5 a}$ as a mixture of diastereomers (2.2:1 ratio) with high enantioselectivity, albeit with a relatively moderate yield. Lower yields were due to the competitive formation of about $10-25 \%$ of bis-indole $6 \mathrm{a}$, presumably formed via the retro-Friedel-Crafts reaction of $1 \mathrm{a}$ followed by $\mathrm{C}_{2}$-alkylation of the resulting 2-methyl-indole. This side reaction could be significantly reduced at lower temperature $\left(-20^{\circ} \mathrm{C}\right)$, thereby improving the yield, but interestingly the reaction produced exclusively the diastereomer 4 a with still a good $92 \%$ ee. Neither concentrating nor diluting the reaction mixture did affect the yield and enantioselectivity (entries 3 and 4). Molecular sieves was not mandatory for the transformation, but was found to slightly increase yields and enantioselectivity (entry 5). Since changing the ratio between both starting materials only marginally affected the reaction outcome (entry 6 vs entry 2), for practical reasons, we adopted a 1.2:1 ratio between 2a:3a for subsequent evaluations. Extensive screening of catalysts and solvents did not improve the yield and enantioselectivity (see Supporting Information, Table S1 and S2). Lowering the reaction temperature did not have a positive impact on both yield and enantioselectivity (entries 7 and 8). However, additional investigation showed that the diastereoselectivity was completely switched at room temperature to form exclusively $\mathbf{5 a}$ in high enantioselectivity (entry 9 ). The retro-Friedel-Crafts 
side reaction accounts for the modest yield (54\%) obtained under these last conditions. To our delight, diastereomer 5 a could be produced in a significantly improved $70 \%$ yield, along with only $10 \%$ of side product $6 \mathrm{a}$, when the reaction was initially performed at $-20^{\circ} \mathrm{C}$ in DCE and subsequently heated to 60 ${ }^{\circ} \mathrm{C}$ for $3 \mathrm{~h}$ (entry 10). This clearly established that $\mathbf{4 a}$ is a kinetic adduct while $\mathbf{5 a}$ represents the thermodynamic one. Furthermore, no erosion of enantioselectivity was observed during the thermodynamic equilibration. The robustness of this diastereodivergent enantioselective ${ }^{x i}$ transformation was demonstrated by a larger scale synthesis of compound $4 \mathrm{a}$ ( $1 \mathrm{mmol}, 70 \%$ yield, $94 \%$ $e e$, entry 11$)$, and $\mathbf{5 a}(0.5 \mathrm{mmol}, 70 \%$ yield, $94 \%$ ee, entry 12$)$.

Table 1. Optimization of catalytic enantioselective synthesis of spiroindolenines.

\begin{tabular}{|c|c|c|c|c|c|}
\hline$\underbrace{P h}_{2 a}$ & $\int_{3 a}^{\mathrm{MHCbz}} \frac{1 \mathrm{a}(5}{\mathrm{solve}}$ & & $4 a$ & $e_{\mathrm{e}}^{\mathrm{Me}}$ or & ${ }_{5 a}^{M e}$ \\
\hline entry & $\mathrm{t}^{\circ} \mathrm{C}$ & $\begin{array}{l}4 a \text { yield } \\
(\%)^{b}\end{array}$ & $\begin{array}{l}4 a \text { ee } \\
(\%)^{c, d}\end{array}$ & $\begin{array}{l}\text { 5a yield } \\
(\%)^{b}\end{array}$ & $\begin{array}{l}5 a \text { ee } \\
(\%)^{c, d}\end{array}$ \\
\hline $1^{a}$ & 0 & 44 & 92 & 20 & 90 \\
\hline $2^{a}$ & -20 & 69 & 92 & - & - \\
\hline $3^{\mathrm{a}, \mathrm{e}}$ & -20 & 67 & 92 & - & - \\
\hline $4^{a, f}$ & -20 & 69 & 92 & - & - \\
\hline $5^{a, g}$ & -20 & 63 & 90 & - & - \\
\hline $6^{h}$ & -20 & 70 & 92 & - & - \\
\hline $7^{h}$ & -30 & 69 & 92 & - & - \\
\hline $8^{h}$ & -40 & 64 & 88 & - & - \\
\hline $9^{h}$ & $\mathrm{rt}$ & - & - & 54 & 86 \\
\hline $10^{i}$ & -20 then 60 & - & - & 70 & 93 \\
\hline $11^{\mathrm{h}, \mathrm{j}}$ & -20 & $70^{d}$ & 94 & - & - \\
\hline $12^{i, \mathrm{i} k}$ & 0 to 60 & - & _ & 70 & 94 \\
\hline
\end{tabular}

${ }^{a}$ General conditions: 2a $(0.10 \mathrm{mmol}), 3 \mathrm{a}(0.15 \mathrm{mmol})$ and $\mathbf{1 a}(5 \mathrm{~mol} \%)$ in $\mathrm{DCM}(0.05 \mathrm{M}){ }^{b}$ Yield of isolated pure product after chromatography. ${ }^{c} \mathbf{4 a}$ refers to absolute $(1 S, 2 S, 5 R, 6 R)$ configuration, $\mathbf{5 a}$ refers to $(1 S, 2 R, 5 R, 6 R)$ configuration, assigned by X-ray crystalstructure analysis of 4a and 5a (see Supporting Information). ${ }^{d}$ Determined by HPLC analysis on a chiral stationary phase. ${ }^{e} \mathrm{C}=0.1 \mathrm{M} .{ }^{f} \mathrm{C}=$ $0.025 \mathrm{M} .{ }^{g}$ Without $4 \AA \mathrm{MS} .{ }^{h}$ General conditions: $\mathbf{2 a}(0.12 \mathrm{mmol}), \mathbf{3 a}(0.10 \mathrm{mmol})$ and $\mathbf{1 a}(5 \mathrm{~mol} \%)$ in DCM $(0.05 \mathrm{M}) .{ }^{i}$ General condition: 2a $(0.10 \mathrm{mmol}), 3 \mathbf{a}(0.12 \mathrm{mmol})$ and $1 \mathbf{a}(5 \mathrm{~mol} \%)$ in DCE $(0.05 \mathrm{M})$ at $-20{ }^{\circ} \mathrm{C}$ for $24 \mathrm{~h}$, then heated at $60{ }^{\circ} \mathrm{C}$ for $3 \mathrm{~h}$. ${ }^{j} \mathrm{With} 1 \mathrm{mmol}$ of $2 \mathbf{a} .{ }^{k}$ With $0.5 \mathrm{mmol}$ of $\mathbf{2 a}$.

Having established the optimal reaction conditions for the formation of the kinetic spiro-product 4, we next explored the substrate scope with a diverse set of dienecarbamates $\mathbf{3}$. In all cases, the $\beta$ spirocyclohexyl-indolenines $\mathbf{4 a - 4 I}$ were obtained with excellent diastereo- and enantioselectivity (Table 1). The $\mathrm{N}$-thiobenzyl- and $\mathrm{N}$-thioallyl-carbamate-substituted dienes were also tolerated, affording the corresponding spiroproducts $\mathbf{4 b}$ to $\mathbf{4 e}$ in similar yields and enantioselectivity. Use of dienecarbamates $\mathbf{4 c}$ and $\mathbf{4 d}$ substituted by linear alkyl groups at the 4-position altered neither yield nor stereoselectivity (95\% ee and $>95: 5 d r$ ). Additional functional groups such as remote unsaturation 
(4f) and silyl ether (4g) were also well tolerated. Notably, the enantioenriched dienecarbamate (prepared from (S)-citronellal) participated in the reaction with equal efficiency. The presence of an additional chiral center did not influence the enantioselective process. Meanwhile, dienes carrying bulkier alkyl groups (such as ${ }^{i}-\operatorname{Pr}$ and ${ }^{i}$-Bu) were found to be compatible with the reaction. The

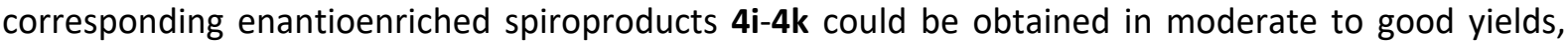
albeit requiring longer reaction times. Subsequently, 4-phenyl-substituted and 4-unsubstituted dienes were studied and the respective products $\mathbf{4 l}$ and $\mathbf{4 h}$ were isolated in relatively lower yield or enantioselectivity, respectively.

Scheme 2. Scope of the enantioselective synthesis of kinetic spirocyclohexyl-indolenines 4.

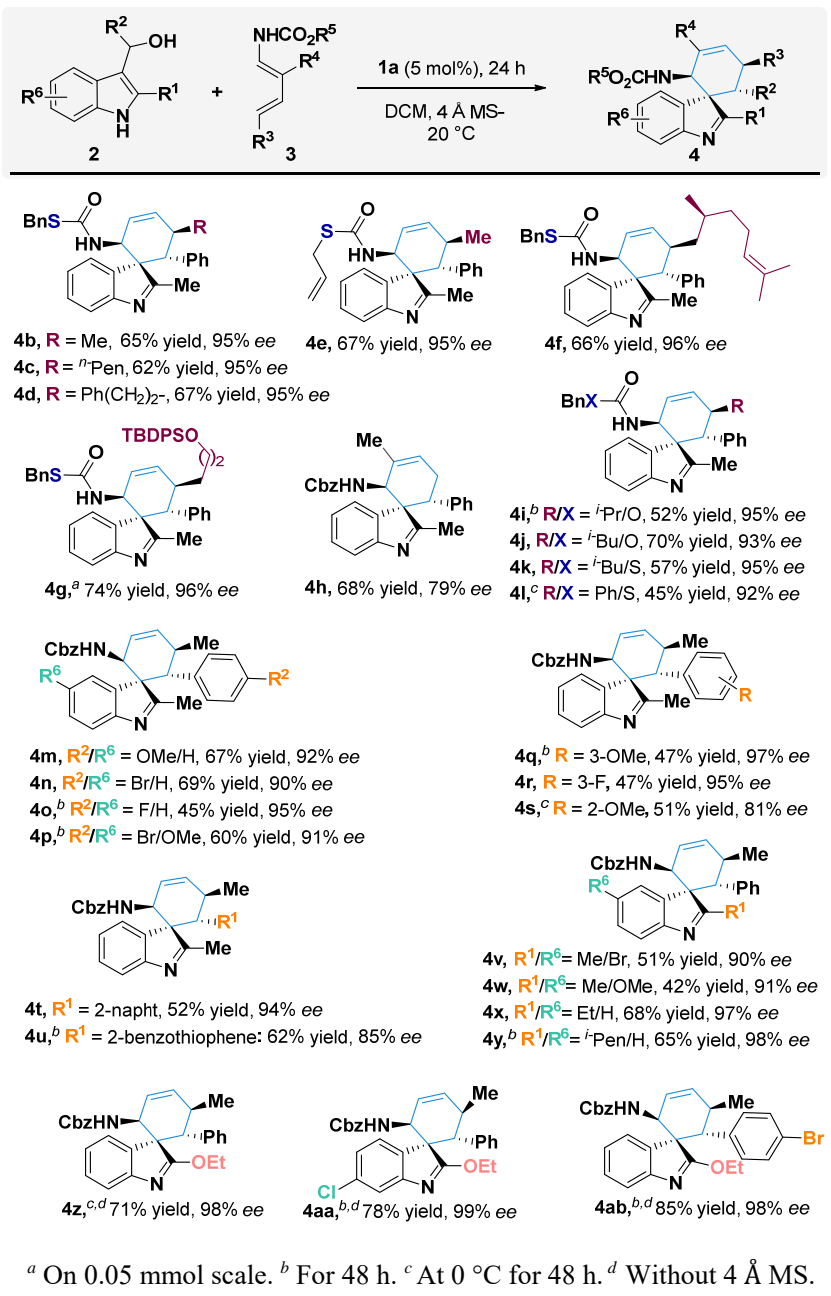

Extension of this enantioselective transformation to other 2-alkylindole-3-methanols $\mathbf{2}$ was successful. Indolyl methanol containing various aryl groups on the side chain with either an electron-donating group or halide group at the ortho-, meta-, and para-positions gave the desired products $4 \mathrm{~m}-4 \mathrm{~s}$ in moderate to good yields and high stereoselectivities. Moreover, the presence of the 2-naphthyl or benzothiophene group was found to be suitable and the corresponding spiroproducts $4 \mathbf{t}-\mathbf{4} \mathbf{u}$ were obtained in lower yields but still with excellent enantioselectivity. Methoxy or halo $(\mathrm{Br}, \mathrm{Cl})$ substitution at the aromatic core of the indoles was also tolerated as exemplified with the synthesis of compound $\mathbf{4 m}, \mathbf{4 v - 4 w}$ and $\mathbf{4 a a}$, obtained in moderate to good yields but with excellent enantioselectivities. Notably, various $\mathrm{C}_{2}$-substituted 3-indolylmethanols bearing diverse alkyl groups, such as ethyl and isopentyl, reacted smoothly to produce the corresponding spiroproducts $\mathbf{4 x}$ and $\mathbf{4 y}$ in decent yields with excellent enantiomeric excesses. Use of 2-phenylindolyl precursor was however not tolerated, 
and only degradation of this latter was observed. In contrast, when 2-ethoxyindole derivatives were used, we were pleased to see that the reaction proceeded smoothly to give the corresponding products $4 \mathbf{z}-\mathbf{4 a b}$ in higher yields (71-85\% yield) with excellent enantioselectivities (up to $99 \%$ ee).

The reaction scope for the synthesis of thermodynamic spiroproducts 5 was also examined. As shown in Scheme 3, 4-substituted dienecarbamates $\mathbf{3}$ were converted to corresponding products $\mathbf{5 b} \mathbf{b} \mathbf{5} \mathbf{f}$ in low to good yields with excellent enantioselectivities. As previously observed, the diene bearing an ${ }^{i}-\mathrm{Pr}$ group delivered product $\mathbf{5 c}$ with a decreased yield, presumably due to the steric hindrance of its bulky side chain. Changing the carbamate group from benzyl to allyl $(\mathbf{5 g}$ and $\mathbf{5 h})$ and ${ }^{t} \mathrm{Bu}(\mathbf{5 i})$ led to similar yields and enantiomeric excesses. A variety of thermodynamic spiroproducts ( $5 \mathbf{j}$ to $\mathbf{5 m}$ ) was obtained with high enantio- and diastereoselectivities from selected 2-alkylindole-3-methanols. This demonstrated that electron-rich and -poor substituents either on the indole core (5m and $\mathbf{5 n}$ ) or on the aryl moiety (5i-5k) were well tolerated. It is also worth noting that our methodology is compatible with various alkyl substituents at the $C_{2}$-position of indoles ( 50 to $\mathbf{5 q}$ ).

Scheme 3. Scope of the enantioselective synthesis of thermodynamic spirocyclohexyl-indolenines 5.

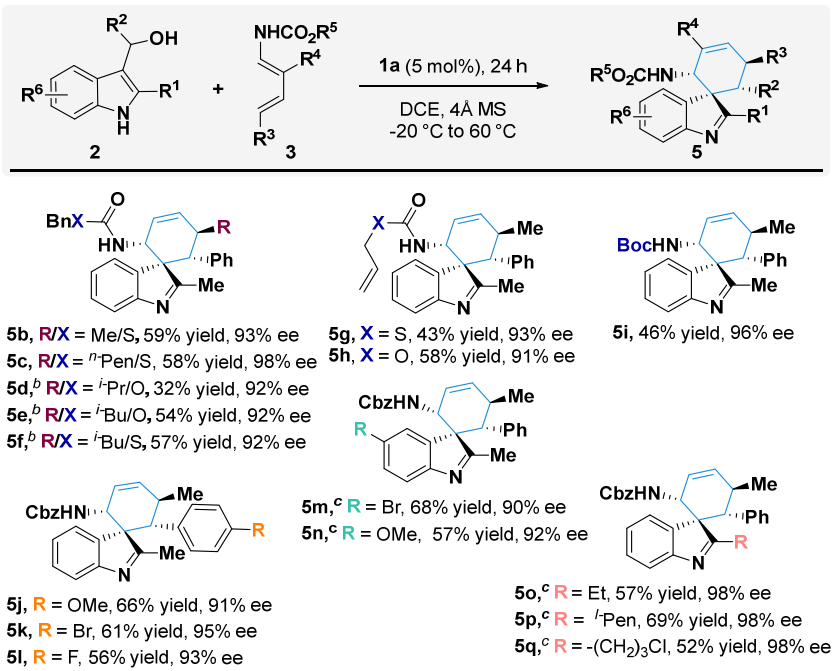

${ }^{a}$ At $0{ }^{\circ} \mathrm{C}$ for $24 \mathrm{~h}$, then at $60{ }^{\circ} \mathrm{C}$ for $3 \mathrm{~h} .{ }^{b} \mathrm{At}-20^{\circ} \mathrm{C}$ for $24 \mathrm{~h}$, then at $60^{\circ} \mathrm{C}$ for $12 \mathrm{~h} .{ }^{c}$ At $-20{ }^{\circ} \mathrm{C}$ for $48 \mathrm{~h}$, then at $60{ }^{\circ} \mathrm{C}$ for $3 \mathrm{~h}$.

Control experiments confirmed that the two diastereomers $\mathbf{4}$ and $\mathbf{5}$ were formed under kinetic and thermodynamic conditions, respectively. Epimerization could be monitored by heating pure spiroproduct 4 a at various temperatures in DCE (Table 2). In the absence of catalyst, no epimerization occurred at room temperature after $15 \mathrm{~h}$ while total epimerization of $4 \mathrm{a}$ to thermodynamic product 5 a was observed in the same amount of time at $60^{\circ} \mathrm{C}$. However, the phosphoric acid catalyst seems to favor the isomerization. Indeed, a complete epimerization took place at room temperature and at 60 ${ }^{\circ} \mathrm{C}$ in respectively $15 \mathrm{~h}$ (entry 2 ) and $5 \mathrm{~min}$ (entry 7 ) in the presence of $5 \mathrm{~mol} \%$ of $1 \mathrm{a}$. In addition, the isomerization of 4 a was complete at $35^{\circ} \mathrm{C}$ in the absence of catalyst 1a applying a $405 \mathrm{~nm}$ irradiation (80\% NMR yield of 5 a after $6 \mathrm{~h}$, entry 4). Interestingly, the reaction performed in $\mathrm{MeOH}$ under such conditions resulted in the formation of the hemiaminal 10a; this trapped iminium intermediate spontaneous cyclizes after its isolation ( $15 \%$ yield) in the NMR tube (entry 5). 
Table 2. Control Experiments Confirm Kinetic and Thermodynamic Product Formation. ${ }^{\mathrm{a}}$

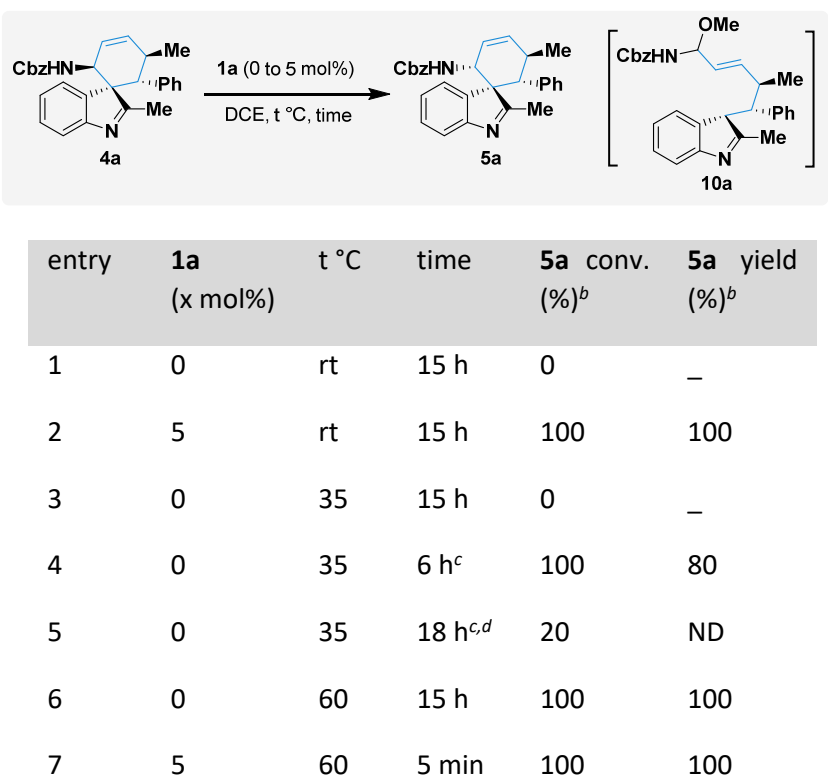

${ }^{a}$ General condition: 4a $(0.05 \mathrm{mmol})$ and $\mathbf{1 a}(5 \mathrm{~mol} \%)$ in DCE $(0.05 \mathrm{M}) .{ }^{b}$ Conversion and yields determined by ${ }^{1} \mathrm{H}$ NMR spectroscopy using $\mathrm{Bn}_{2} \mathrm{O}$ as standard intern. ${ }^{c}$ irradiated with EvoluChem, P206-18-1 at $405 \mathrm{~nm}, 28 \mathrm{~mW} / \mathrm{cm}^{2} .^{d} \mathrm{In} \mathrm{MeOH}$.

Based on these experiments and our previous mechanistic studies, ${ }^{6}$ a catalytic cycle of the enantioselective spirocyclization was proposed. Even though we were not able to identify any iminium (or trapped intermediate 10a) under the catalyzed process (see Supporting Information, Scheme S2) ) $^{\mathrm{ii}}$ we privileged a stepwise mechanism. The vinylindoliniminium ion is formed upon initial chiral phosphoric acid 1a mediated dehydration of 2-alkyl-3-indolylarlymethanols $\mathbf{2}$, furnishing complex $\mathbf{7}$ (Scheme 4). Then, dienecarbamate 3 reacts with the vinyliminium complex $\mathbf{7}$ to form the iminium intermediate 8. The latter undergoes an intramolecular $\mathrm{C}_{3}$ aza-alkylation of indolylmethane delivering iminium 9 that produces the desired $\beta$ spirocyclohexyl-indolenines 4 . Finally, the kinetic product isomerizes to yield the thermodynamically more stable spiroproduct $\mathbf{5}$ via iminium intermediate $\mathbf{9}$ '. The stepwise isomerization mechanism is consistent with the isolation of intermediate 10a.

Scheme 4. Plausible reaction mechanism.

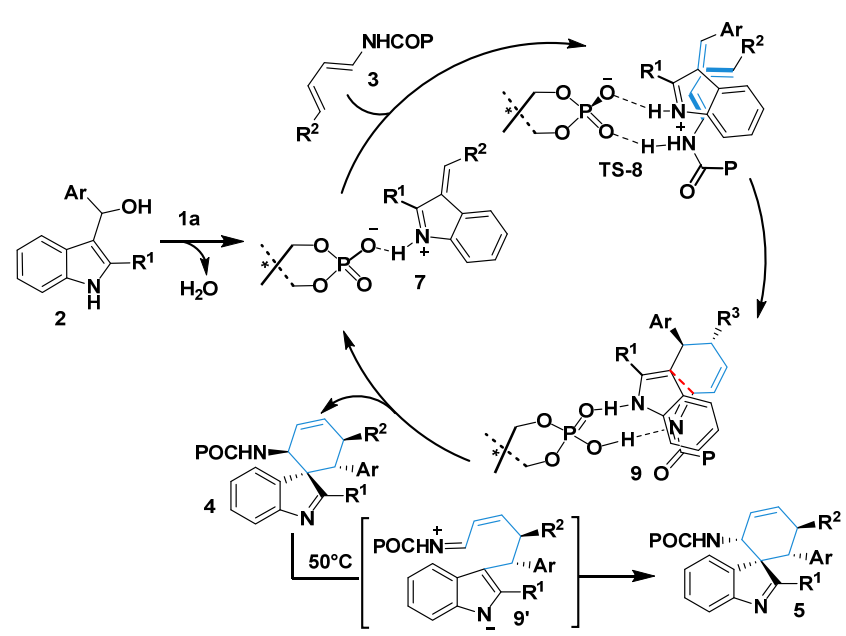

A computational study was undertaken at the M06-2X/6-311+G(d,p)//M06-2X/6-31G(d) level of theory in order to get deeper insight into the mechanism and importantly to rationalize the observed stereochemistry of 5. Initial calculations investigated according the above mechanism did however 
furnish a conflicting result, as it provided systematically the wrong enantiomer. The details are provided in the Supporting Information (Schemes S3 to S6). As such it questioned the dual activation of the vinyliminium and the dienecarbamate by the chiral phosphoric acid 1a (TS-8, Scheme 4). This finding required the reevaluation of the mechanism of this spirocyclization. Our novel set of computations clearly indicated that the process of water abstraction from the indolylalcohol had to be taken into account and that the resulting $\mathrm{H}$-bonded water molecule could play a major role in the stereoselectivity. ${ }^{\text {xiiixiv }}$ Figure 1 shows what we believe fully rationalizes our experimental findings. As reference system, we chose indolylmethanol $\mathbf{2} \mathbf{a}$, the s-trans diene $\mathbf{3 a}$ and the model catalyst $\mathbf{1} \mathbf{b}$. The $\mathrm{s}$-cis diene $3 \mathbf{a}^{\prime}$ ' was found $3.0 \mathrm{kcal} / \mathrm{mol}$ less stable than $\mathbf{3 a}$. The formation of a $\mathrm{H}$-bond between the alcohol functionality of $\mathbf{2 a}$ and the acidic proton of $\mathbf{1 b}$ leads to $\mathbf{B}$, with the release of $4.8 \mathrm{kcal} / \mathrm{mol}$ of free energy. Cleavage of the $\mathrm{C}-\mathrm{O}$ bond provides intermediate $\mathrm{C}^{\mathrm{xv}}$ which is of course axially chiral by the phosphate side, but this especially induces planar chirality as the water molecule is located on the lower face of the vinylindoliniminium ion framework when the Me group is oriented to the right. The corresponding transition state, $\mathbf{T S}_{\mathbf{B C}}$, lies at $12.5 \mathrm{kcal} / \mathrm{mol}$ on the free energy surface and this step is endergonic by $4.3 \mathrm{kcal} / \mathrm{mol}$. The diastereomers of $\mathbf{B}$ and $\mathbf{C}, \mathbf{B}^{\prime}$ and $\mathbf{C}^{\prime}$, are shown on the lower energy profile. While these intermediates are virtually as stable as $\mathbf{B}$ and $\mathbf{C}, \mathbf{T S}_{\mathbf{B}^{\prime} \mathbf{C}^{\prime}}$ is $0.9 \mathrm{kcal} / \mathrm{mol}$ less stable than $\mathbf{T S}_{\mathbf{B C}}$. An adduct is then formed between $\mathbf{3} \mathbf{a}^{\prime}$ and the vinylindoliniminium species $\mathbf{C}$ or $\mathbf{C}^{\prime}$, which can only occur on the face opposite to water. Of note, in $\mathbf{D}$ and $\mathbf{D}^{\prime}$, the carbamate is oriented as to give an endo adduct in the Diels-Alder sense of the word. The exo-orientation did not allow any subsequent C-C bond formation. $\mathbf{D}^{\prime}$ is markedly less stable than $\mathbf{D}$ by $4.3 \mathrm{kcal} / \mathrm{mol}$ (from -0.9 to $3.4 \mathrm{kcal} / \mathrm{mol}$ ). The last step is an asynchronous $(4+2)$ cycloaddition furnishing the spiro adduct $\mathbf{E}$ or $\mathbf{E}^{\prime}$, which are equally stable. However, $\mathbf{T S}_{\mathrm{DE}^{\prime}}$ is $4.2 \mathrm{kcal} / \mathrm{mol}$ more stable than $\mathbf{T S}_{\mathrm{D}^{\prime} \mathrm{E}^{\prime}}$ (from 12.1 to $16.3 \mathrm{kcal} / \mathrm{mol}$ ). Comparison of these two profiles clearly indicates that the formation of $\mathbf{E}$ is kinetically preferred over that of $\mathbf{E}^{\prime}$. The absolute configuration of $\mathbf{E}$ matches that of the experimentally observed kinetic product (KP) $4 \mathbf{a}$ $(R, R$ configuration), located at $-12.5 \mathrm{kcal} / \mathrm{mol}$ on the free energy surface. The corresponding thermodynamic product (TP) $\mathbf{5}$ a was found at $-14.3 \mathrm{kcal} / \mathrm{mol}$. While the $S$ enantiomer of $\mathbf{B}$ shown in the upper part of Figure 1 reacts faster than the $R$ enantiomer depicted in the lower part, we observed no kinetic resolution in this transformation. Thus, the two profiles must be connected in some way by transition states of lower energies than those already discussed to allow a dynamic kinetic resolution. We found indeed than $\mathbf{C}$ and $\mathbf{C}^{\prime}$ are in fast equilibrium (see the Supporting Information, Scheme S7).Thus, based on these computations and all the other options summarized in the Supporting Information, we can conclude that the planar chirality of the vinylindoliniminium ion intermediate controls the enantioselectivity of the formal cycloaddition reaction.

To experimentally confirm that no specific Lewis base activation of the dienecarbamate was required for overall reactivity, we performed a series of experiments involving other Brønsted acid catalysts (see the Supporting Information, Scheme S1 and Table S3). When TFA (50 mol\%) was employed, a 1:1 mixture of $\mathbf{4 a}$ and $\mathbf{5 a}$ were formed in $47 \%$ yield. In addition, the reaction conducted in the presence of (+)-CSA (20 mol\%) led to $4 a$ in $51 \%$ yield with $28 \%$ ee. These results are in full agreement with the computed transition state in which the chiral phosphate counterion controls the stereochemical outcome of the reaction. They also concur with a mono-activation of $\mathbf{2}$ by the catalyst. ${ }^{\mathrm{xi}}$

In light of these experimental and computational data, the initially proposed mechanism (Scheme 4) was adjusted as shown in scheme 5. As originally proposed, the reaction begins with the formation of a chiral vinyliminium phosphate ion pair upon treatment of $\mathbf{2}$ with catalyst 1a. However, in contrast to our initial thought, water stays coordinate to $1 \mathrm{a}$, generating a stable complex, which undergoes the addition of the dienecarbamate $\mathbf{2}$ in an asynchronous concerted manner through a well-organized transition state TS-10. Finally, the catalyst $\mathbf{1 a}$ is liberated upon release of water, which is trapped by molecular sieves. 
Scheme 5. Revisited reaction mechanism.

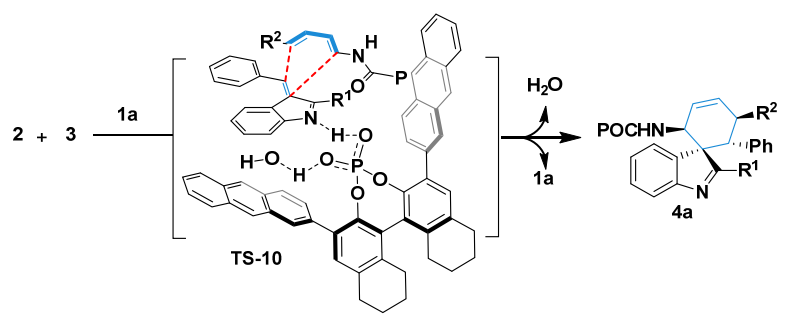

The value of kinetic and thermodynamic spirocyclic compound $\mathbf{4 a}, \mathbf{4 a b}$ and $\mathbf{5 a}$, prepared by the novel catalytic process was further illustrated by performing various stereospecific transformations (Scheme $6)$.

Scheme 6. Stereospecific Derivatizations of Spiroindolenines into Spiroindolines and Spirooxindoles
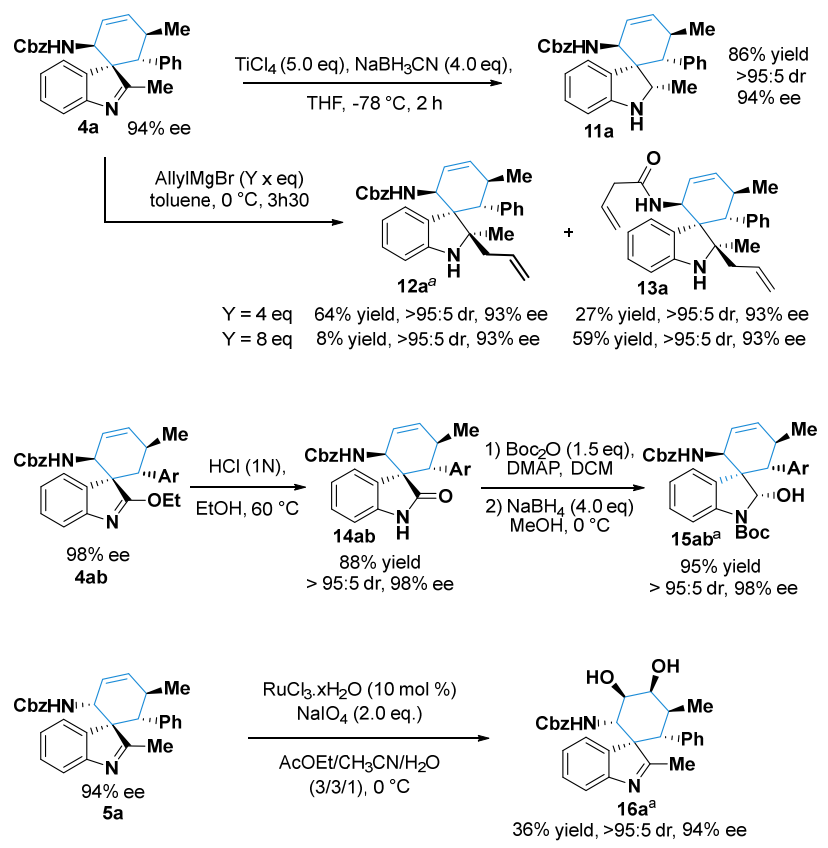

${ }^{a}$ The relative configuration was assigned by NOESY experiments (See Supporting Information).

For instance, chiral spiroindolenine 4a was reduced with $\mathrm{NaBH}_{3} \mathrm{CN}$ and $\mathrm{TiCl}_{4}$ to provide the corresponding indolenine $11 \mathrm{a}$ in $84 \%$ yield as a single diastereomer bearing five fully defined stereocenters and with no erosion of enantioselectivity. The absolute configuration of 11a was confirmed by $\mathrm{X}$-ray diffraction. The reduction was also realized in a sequential one-pot process, which avoids the purification of the spiroindolenine 4 a. Under sequential process, the spiroindoline 11a was isolated in $58 \%$ overall yield (corresponding to the sum of the yields of individual step) with $90 \%$ ee as a single diastereomer (See Supporting Information). Addition of allylmagnesium bromide to 4 a proceeded with complete diastereoselectivity leading to the formation of two products: the expected allylated spiroindoline 12a and the double allylated spiroindoline 13a in a 7:3 ratio, respectively. Both products were readily separated by column chromatography and isolated without loss of enantioselectivity. When an excess of allylmagnesium bromide was used, the double allylated spiroindoline 13a was formed as major compound in better yield. In addition, the acetamidate product 4ab was submitted to hydrolysis and the spirooxindole 14ab was produced in good yield with no loss of enantioselectivity. The resulting product 14ab was protected with Boc and then reduced with $\mathrm{NaBH}_{4}$ to give the spiro-aminal 15ab with excellent diastereoselectivity (>95:5). Finally, the thermodynamic 
spiroproduct 5a could undergo a dihydroxylation to give the highly substituted enantioenriched spiroproduct 16a in moderate yield albeit with full diastereocontrol of six contiguous stereogenic centers give the spiro-aminal 15ab with excellent diastereoselectivity (>95:5). Finally, the thermodynamic spiroproduct 5a could undergo a dihydroxylation to give the highly substituted enantioenriched spiroproduct 16a in moderate yield albeit with full diastereocontrol of six contiguous stereogenic centers

\section{CONCLUSION}

In summary, we developed a novel enantioselective and diastereodivergent spirocyclizations of 2susbtituted 3-indolylmethanols with 1,3-dienecarbamates by a chiral phosphoric acid. In this reaction, a variety of valuable chiral polysubstituted spirocyclohexyl-indolenines bearing four contiguous stereogenic centers, including one spiro quaternary center, were conveniently constructed with excellent enantioselectivities and diastereoselectivities. The [4+2] cycloaddition, can be directed to different diastereomers of the spiroindolenine simply through temperature change, moving from kinetic to thermodynamic control. Besides, chiral spiroindolenines were amenable to further transformations and converted into enantioenriched spiroindolenines and spirooxindoles. DFT calculation and experimental findings corroborate an asynchronous concerted mechanism with a mono activation of chiral phosphoric acid. Finally, this also revealed the fundamental role played by a water molecule in the transition state accounting for the enantioselectivity.

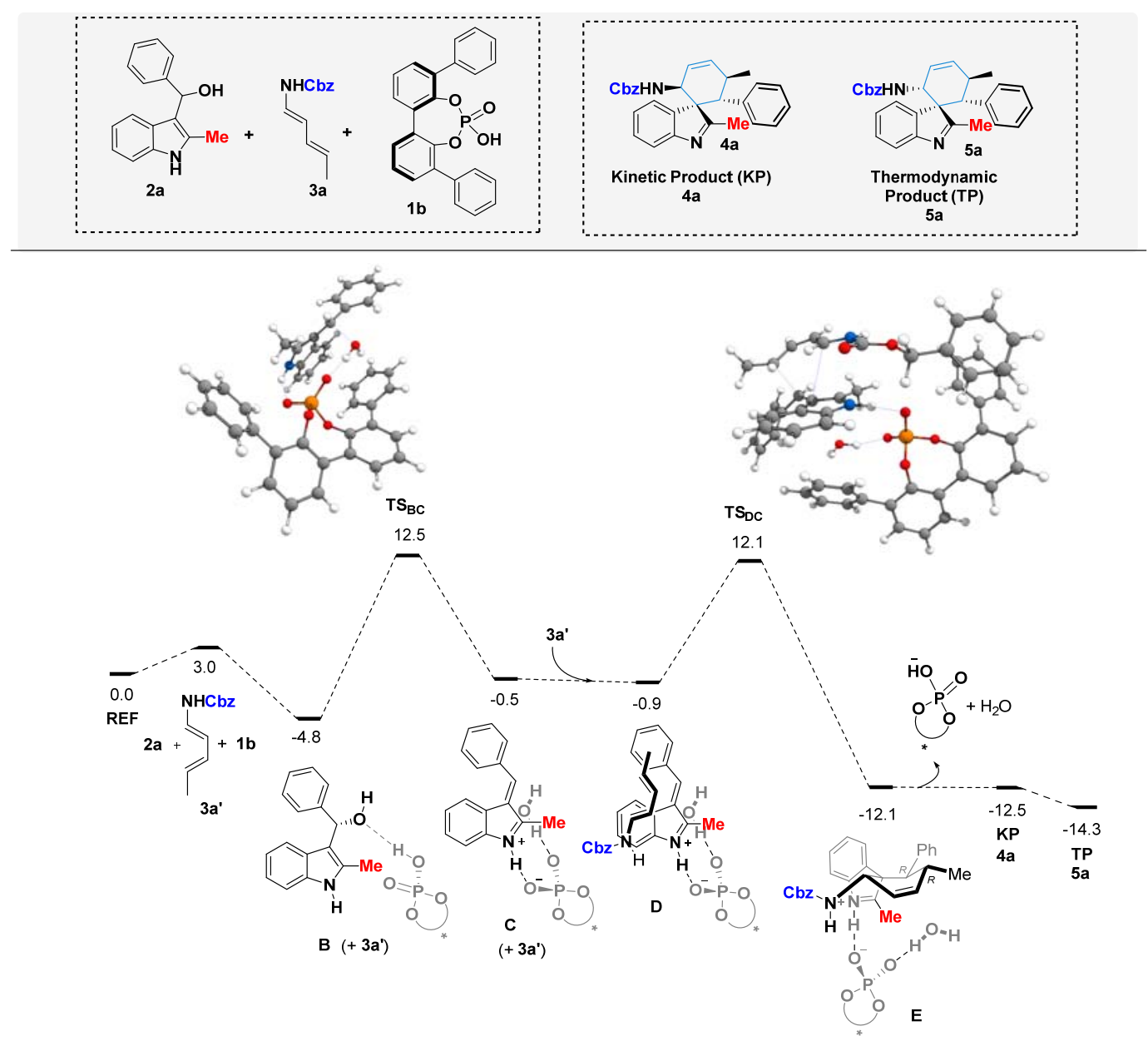




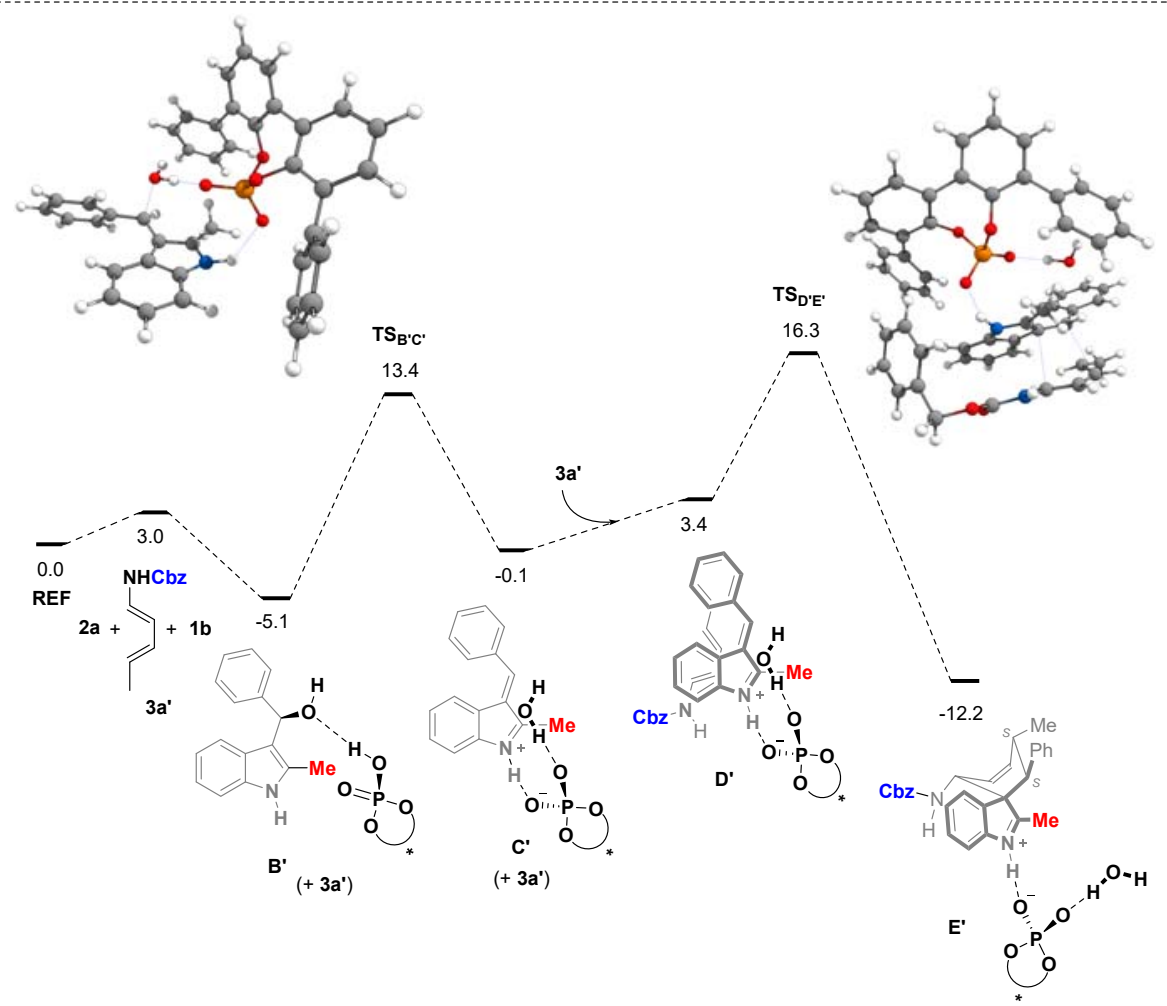

Figure 1. Computed free energy profiles $\left(\Delta G_{253}, \mathrm{kcal} / \mathrm{mol}\right)$.

(i) Selected recent reviews: (a) Bariwal, J.; Voskressensky, L. G.; Van der Eycken, E. V. Recent Advances in Spirocyclization of Indole Derivatives. Chem. Soc. Rev. 2018, 47, 3831. (b) Ding, A.; Meazza, M.; Guo, H.; Yang; J. W.; Rios. R. New Development in the Enantioselective Synthesis of Spiro Compounds, Chem. Soc. Rev. 2018, 47, 5946. (c) James, M. J.; O’Brien, P.; Taylor, R. J. K. Unsworth, W. P. Synthesis of Spirocyclic Indolenines. Chem.-Eur. J. 2016, 22, 2856. (d) Wang, Y.; Xie, F.; Lin, B.; Cheng, M.; Liu, Y. Synthetic Approaches to Tetracyclic Indolines as Versatile Building Blocks of Diverse Indole Alkaloids. Chem.-Eur. J. 2018, 24, 14302. (e) Ling, T.; Rivas, F. All-carbon Quaternary Centers in Natural Products and Medicinal Chemistry: Recent Advances. Tetrahedron 2016, 72, 6729. (f) Zheng; Y. J.; Tice, C. M. The Utilization of Spirocyclic Scaffolds in Novel Drug Discovery. Expert Opin. Drug Discovery, 2016, 11, 831. (g) Smith, L. K.; Baxendale, I. R. Total Syntheses of Natural Products Containing Spirocarbocycles. Org. Biomol. Chem. 2015, 13, 9907. (h) Zheng, Y.; Tice, C. M. Singh, S. B. The Use of Spirocyclic Scaffolds in Drug Discovery. Bioorg. Med. Chem. Lett. 2014, 24, 3673.

(ii) Selected recent examples: (a) Zheng, C.; You, S.-L. Exploring the Chemistry of Spiroindolenines by Mechanistically-Driven Reaction Development: Asymmetric Pictet-Spengler-type Reactions and Beyond. Acc. Chem. Res. 2020, 53, 974. (b) Rao, R. N.; Maiti, B.; Chanda, K. Application of Pictet-Spengler Reaction to Indole-Based Alkaloids Containing Tetrahydro- $\beta$-carboline Scaffold in Combinatorial Chemistry. ACS Comb. Sci. 2017, 19, 199. (c) Stöckigt, J.; Antonchick, A. P.; Wu, F.; Waldmann, H.; The Pictet-Spengler Reaction in Nature and in Organic Chemistry. Angew. Chem., Int. Ed. 2011, 50, 8538.

(iii) Selected recent reviews: (a) Xu, P.-W.; Yu, J.-S.; Chen, C.; Cao, Z.-Y.; Zhou, F.; Zhou, J. Catalytic Enantioselective Construction of Spiro Quaternary Carbon Stereocenters. ACS Catalysis 2019, 9, 1820. (b) Huang, G.; Yin, B. Recent Developments in Transition Metal-Catalyzed Dearomative Cyclizations of Indoles as Dipolarophiles for the Construction of Indolines. Adv. Synth. Catal. 2019, 361, 405. (c) Xie, X.; Huang, W.; Peng, C.; Han, B. Organocatalytic Asymmetric Synthesis of Six-Membered Carbocycle-Based Spiro Compounds. Adv. Synth. Catal. 2018, 360, 194. (d) Roche, S. P.; Youte Tendoung, J.-.; Tréguier, B. Advances in Dearomatization Strategies of Indoles. Tetrahedron 2015, 71, 3549. (e) D'yakonov, V. A.; Trapeznikova, O. A.; de Meijere, A.; Dzhemilev, U. M. Metal Complex Catalysis in the Synthesis of Spirocarbocycles. Chem. Rev. 2014, 114, 5775. (f) Ding, Q.; Zhou, X.; Fan, R. Recent Advances in Dearomatization of Heteroaromatic Compounds. Org. Biomol. Chem. 2014, 12, 4807. (g) Franz, A. K.; Hanhan, N. V.; Ball-Jones, N. R. Asymmetric Catalysis for the Synthesis of Spirocyclic Compounds. ACS Catal. 2013, 3, 540. (h) Rios, R. Enantioselective Methodologies for the Synthesis of Spiro Compounds. Chem. Soc. Rev. 2012, 41, 1060.

(iv) Selected recent reviews: (a). Boddy, A. J.; Bull, J. A. Stereoselective Synthesis and Applications of Spirocyclic Oxindoles. Org. Chem. Front., 2021, 8, 1026. (b) Sakla, A. P.; Kansal, P.; Shankaraiah, N. Syntheses and Reactivity of Spiro-epoxy/Aziridine Oxindole Cores: Developments in the Past Decade. Org. Biomol. Chem. 2020, 18, 8572-8596. (c) Mei, G.-J.; Shi, F. Catalytic Asymmetric Synthesis of Spirooxindoles: Recent Developments. Chem. Commun. 2018, 54, 6607. (b) Fang, X.; Wang, C.-J. Catalytic Asymmetric Construction of Spiropyrrolidines via 1,3Dipolar Cycloaddition of Azomethine Ylides. Org. Biomol. Chem. 2018, 16, 2591. (d) Cheng, D.; Ishihara, Y.; Tan, B.; Barbas III, C. F. Organocatalytic Asymmetric Assembly Reactions: Synthesis of Spirooxindoles via Organocascade Strategies. ACS Catal. 2014, 4, 743. (e) Hong, L.; Wang, R. Recent Advances in Asymmetric Organocatalytic Construction of 3,3' - Spirocyclic Oxindoles. Adv. Synth. Catal. 2013, 355, 1023. (f) Ball-Jones, N. R.; Badillo, J. J.; Franz, A. K. Strategies for the Enantioselective Synthesis of Spirooxindoles. Org. Biomol. Chem. 2012, 10, 5165. (g) Singh, G. S.; Desta, Z. Y. Isatins As Privileged Molecules in Design and Synthesis of Spiro-Fused Cyclic Frameworks. Chem. Rev. 2012, 112,6104 . 
(") (a) Magné, V.; Marinetti, A.; Gandon, V.; Voituriez, A. Guinchard, X. Synthesis of Spiroindolenines via Regioselective Gold(I)-Catalyzed Cyclizations of N-Propargyl Tryptamines. Adv. Synth. Catal. 2017, 22, 4036. (b) Wang, Y., Zheng, C.; You, S.-L. Iridium-Catalyzed Asymmetric Allylic Dearomatization by a Desymmetrization Strategy. Angew. Chem., Int. Ed. 2017, 56, 15093. (c) Xia, Z.-L.; Zheng, C.; Wang, S.-G.; You, S.L. Catalytic Asymmetric Dearomatization of Indolyl Dihydropyridines through an Enamine-Isomerization/Spirocyclization/Transfer Hydrogenation Sequence. Angew. Chem., Int. Ed. 2018, 57, 2653. (d) Zhang, Y.-Y.; Wei,Y.; Shi, M. Catalyst-Controlled Product Selectivity for Cycloaddition of Bis(indol-3-yl)-allenes to Fused Spiroindolines and Mechanistic Studies. Org. Lett. 2019, 21, 8250. (e) Becker, A.; Grugel, C. P.; Breit, B. Rhodium-Catalyzed Stereoselective Cyclization of 3-Allenylindoles and N-Allenyltryptamines to Functionalized Vinylic Spiroindolenines, Org. Lett. 2021, doi: 10.1021/acs.orglett.1c01234.

(vi) (a) Gelis, C.; Levitre, G.; Merad, J.; Retailleau, P.; Neuville, L., Masson, G. Highly Diastereo- and Enantioselective Synthesis of Cyclohepta[b]indoles via Chiral Phosphoric Acid-Catalyzed [4+3] Cycloaddition. Angew. Chem., Int. Ed. 2018, 57, 12121. Selected examples of enantioselective formal cycloadditions using enecarbamates or dienecarbamates: (b) Ma, W.-Y.; Gelis, C.; Bouchet, D.; Retailleau, P.; Moreau, X.; Neuville, L.; Masson, G. Chiral Phosphoric Acid-Catalyzed Enantioselective Construction of 2,3-Disubstituted Indolines. Org. Lett., 2021, 23, 442. (c) Varlet, T.; Gelis, C.; Retailleau, P; Bernadat, G.; Neuville, L; Masson, G. Redox-Divergent Chiral Phosphoric Acid-Catalyzed Enantioselective Formal Quinone Diels-Alder Reactions. Angew. Chem., Int. Ed. 2020, 59, 8491. (d) Jarrige, L.; Glavač, D.; Levitre, G.; Retailleau, P.; Bernadat, G.; Neuville, L.; Masson, G. Chiral Phosphoric Acid-Catalyzed Enantioselective Construction of Structurally Diverse Benzothiazolopyrimidines. Chem. Sci. 2019, 10, 3765. (e) Gelis, C.; Bekkaye, M.; Lebée, C.; Blanchard, F.; Masson, G. Chiral Phosphoric Acid Catalyzed [3+2] Cycloaddition and Tandem Oxidative [3+2] Cycloaddition: Asymmetric Synthesis of Substituted 3-Aminodihydrobenzofurans. Org. Lett. 2016, 18, 3422. (f) Lebée, C.; Kataja, A. O.; Blanchard, F.; Masson, G. Formal Asymmetric Organocatalytic [3 + 2] Cyclization between Enecarbamates and 3-Indolylmethanols - a Rapid Access to 3-Aminocyclopenta[b]indoles. Chem. Eur. J. 2015, 21, 8399. (g) Pous, J.; Courant, T.; Bernadat, G.; loga, B. I.; Blanchard, F.; Masson, G. Regio-, Diastereo-, and Enantioselective Nitroso-Diels-Alder Reaction of 1,3-Diene-1carbamates Catalyzed by Chiral Phosphoric Acids. J. Am. Chem. Soc. 2015, 137, 11950.

$\left({ }^{\text {vii }) ~ S e l e c t e d ~ r e c e n t ~ r e v i e w s ~ o n ~ c h i r a l ~ p h o s p h o r i c ~ a c i d ~ c a t a l y s i s: ~(a) ~ S h a o, ~ Y .-D . ; ~ C h e n g, ~ D .-J . ~ C h i r a l ~ P h o s p h o r i c ~ A c i d: ~ A ~ P o w e r f u l ~ O r g a n o c a t a l y s t ~}\right.$ for the Asymmetric Synthesis of Heterocycles with Chiral Atropisomerism. ChemCatChem 2021, 13, 1271 (b), Nunes, P. S. G.; Vidal, H. D. A. Corrêa, A. G. Recent Advances in Catalytic Enantioselective Multicomponent Reactions. Org. Biomol. Chem. 2020, 18, 7751.(c) Merad, J.; Lalli, C.; Bernadat, G.; Maury, J.; Masson, G. Enantioselective Brønsted Acid Catalysis as a Tool for the Synthesis of Natural Products and Pharmaceuticals. Chem. Eur. J. 2018, 24, 3925. (d) Parmar, D.; Sugiono, E.; Raja, S.; Rueping, M. Complete Field Guide to Asymmetric BINOLPhosphate Derived Brønsted Acid and Metal Catalysis: History and Classification by Mode of Activation; Brønsted Acidity, Hydrogen Bonding, Ion Pairing, and Metal Phosphates. Chem. Rev. 2017, 117, 10608; Chem. Rev. 2014, 114, 9047. (e) Akiyama, T.; Mori, K. Stronger Brønsted Acids: Recent Progress. Chem. Rev. 2015, 115, 9277. (f) Schenker, S.; Zamfir, A.; Freund, M.; Tsogoeva, S. B. Developments in Chiral BinaphthylDerived Brønsted/Lewis Acids and Hydrogen-Bond-Donor Organocatalysis. Eur. J. Org. Chem. 2011, 2209. (g) Rueping, M.; Kuenkel, A.; Atodiresei, I. Chiral Brønsted Acids in Enantioselective Carbonyl Activations - Activation Modes and Applications. Chem. Soc. Rev. 2011, 40, 4539. (h) Kampen, D.; Reisinger, C. M.; List, B. Chiral Brønsted Acids for Asymmetric Organocatalysis. Top. Curr. Chem. 2010, 291, 395. (i) Terada, M. Chiral Phosphoric Acids as Versatile Catalysts for Enantioselective Carbon-Carbon Bond Forming Reactions. Bull. Chem. Soc. Jpn. 2010, 83, 101. (j) Terada, M. Chiral Phosphoric Acids as Versatile Catalysts for Enantioselective Transformations. Synthesis 2010, 1929. (k) Akiyama, T. Stronger Brønsted Acids. Chem. Rev. 2007, 107, 5744. (I) Akiyama, T.; Itoh, J.; Fuchibe, K. Recent Progress in Chiral Brønsted Acid Catalysis. Adv. Synth. Catal. 2006, 348, 999.

(viii) Selected reviews on utilization of enamides and dienamides: (a) Varlet, T.; Masson G. Enamides and Dienamides in Phosphoric AcidCatalysed Enantioselective Cycloadditions for the Synthesis of Chiral amines. Chem. Commun. 2021, 57, 4089. (b) Zhu, T.; Xie, S.; Rojsitthisak, P.; Wu, J. Recent advances in the direct $\beta-C\left(s p^{2}\right)-H$ functionalization of enamides. Org. Biomol. Chem., 2020, 18, 1504. (c) Beltran, F.; Miesch, L. Tertiary Enamides as Versatile and Valuable Substrates to Reach Chemical Diversity. Synthesis 2020, 52, 2497. (d) Gigant, N.; ChaussetBoissarie, L.; Gillaizeau, I. Direct Metal-Catalyzed Regioselective Functionalization of Enamides. Chem.-Eur. J. 2014, 20, 7548. (e) Gopalaiah; K.; Kagan, H. B, Use of Nonfunctionalized Enamides and Enecarbamates in Asymmetric Synthesis. Chem. Rev. 2011, 111, 4599. (f) Carbery, D. R. Enamides: valuable organic substrates Org. Biomol. Chem. 2008, 6, 3455. (g) Matsubara, R.; Kobayashi, S. Enamides and Enecarbamates as Nucleophiles in Stereoselective C-C and C-N Bond-Forming Reactions. Acc. Chem. Res. 2008, 41, 292.

$\left({ }^{i x}\right)$ For the first examples using dienecarbamates in cycloadditions: (a) Overman, L. E.; Jessup, P. J. Synthetic Applications of N-Acylamino-1,3dienes. An Efficient Stereospecific Total Synthesis of dl-Pumiliotoxin C, and a General Entry to cis-Decahydroquinoline alkaloids. J. Am. Chem. Soc.1978, 100, 5179. (b) Overman, L. E.; Freerks, R. L.; Petty, C. B.; Clizbe, L. A.; Ono, R. K.; Taylor, G. F.; Jessup, P. J. Diels-Alder Reactions of 1(Acylamino)-1,3-Dienes. J. Am. Chem. Soc. 1981, 103, 2816. (c) Overman, L. E.; Lesuisse, D.; Hashimoto, M. Synthetic Applications of NAcylamino-1,3-dienes. 10. Importance of Allylic Interactions and Stereoelectronic Effects in Dictating the Steric Course of the Reaction of Iminium lons with Nucleophiles. An efficient Total Synthesis of (.+-.)-Gephyrotoxin. J. Am. Chem. Soc. 1983, 105, 5373. Selected examples of enantioselective cycloadditions with dienecarbamates: (d) Huang, Y.; Iwama, T.; Rawal, V. H. Broadly Effective Enantioselective Diels-Alder Reactions of 1-Amino-substituted-1,3-butadienes. Org. Lett. 2002, 4, 1163. (e) Momiyama, N.; Konno, T., Furiya, Y.; Iwamoto, T.; Terada, M. Design of Chiral Bis-phosphoric Acid Catalyst Derived from (R)-3,3'-Di(2-hydroxy-3-arylphenyl)binaphthol: Catalytic Enantioselective DielsAlder Reaction of $\alpha, \beta$-Unsaturated Aldehydes with Amidodienes. J. Am. Chem. Soc. 2011, 133, 19294. (f) Caruana, L.; Fochi, M.; Ranieri, S.; Mazzanti, A.; Bernardi, L. Catalytic Highly Enantioselective Vinylogous Povarov Reaction. Chem. Commun. 2013, 49, 880. (g) Momiyama, N.; Funayama, K.; Noda, H.; Yamanaka, M.; Akasaka, N.; Ishida, S.; Iwamoto, T.; Terada, M. Hydrogen Bonds-Enabled Design of a C1-Symmetric Chiral Brønsted Acid Catalyst. ACS Catal. 2016, 6, 949. (h) Momiyama, N.; Tabuse, H.; Noda, H.; Yamanaka, M.; Fujinami, T.; Yamanishi; K.; Izumiseki, A; Funayama, K.; Egawa, F.; Okada, S.; Adachi, H.; Terada, M. Molecular Design of a Chiral Brønsted Acid with Two Different Acidic Sites: Regio-, Diastereo-, and Enantioselective Hetero-Diels-Alder Reaction of Azopyridinecarboxylate with Amidodienes Catalyzed by Chiral Carboxylic Acid-Monophosphoric Acid. J. Am. Chem. Soc. 2016, 138, 11353. (i) Nishikawa, Y.; Nakano, S.; Tahira, Y.; Terazawa, K.; Yamazaki, K.; Kitamura, C.; Hara, O. Chiral Pyridinium Phosphoramide as a Dual Brønsted Acid Catalyst for Enantioselective Diels-Alder Reaction. Org. Lett. 2016, 18, 2004. See also, ref 6a, 6c and $6 \mathrm{~g}$.

( ${ }^{x}$ ) Selected reviews: (a) Mei, G.-J.; Shi, F. Indolylmethanols as Reactants in Catalytic Asymmetric Reactions. J. Org. Chem. 2017, 82, 7695. (b) Kataja, A. O.; Masson, G. Imine and Iminium Precursors as Versatile Intermediates in Enantioselective Organocatalysis. Tetrahedron 2014, 70, 8783-8815. (c) Wang, L.; Chen, Y.; Xiao, J. Alkylideneindoleninium lons and Alkylideneindolenines: Key Intermediates for the Asymmetric Synthesis of 3 - Indolyl Derivatives. Asian J. Org. Chem. 2014, 3, 1036. (d) Chen, L.; Yin, X.-P.; Wang, C.-H.; Zhou, J.; Catalytic Functionalization of Tertiary Alcohols to Fully Substituted Carbon Centres. Org. Biomol. Chem. 2014, 12, 6033. (e) Palmieri, A.; Petrini, M.; Shaikh, R. R. Synthesis of 3-Substituted Indoles via Reactive Alkylideneindolenine Intermediates Org. Biomol. Chem. 2010, 8, 1259.

( ${ }^{\mathrm{xi}}$ ) A Selected review: (a) Beletskaya, I. P.; Nájera, C.; Yus, M. Stereodivergent Catalysis. Chem. Rev. 2018, 118, 5080. (b) Krautwald, S.; Carreira, E. M. Stereodivergence in Asymmetric Catalysis. J. Am. Chem. Soc. 2017, 139, 5627. (c) Bihani, M.; Zhao, J. C.-G. Advances in Asymmeirik 
Diastereodivergent Catalysis. Adv. Synth. Catal. 2017, 359, 534. (d) Schindler, C. S.; Jacobsen, E. N. A New Twist on Cooperative Catalysis. Science 2013, 340, 1052. (e) Oliveira, M. T.; Luparia, M.; Audisio, D.; Maulide, N. Dual Catalysis Becomes Diastereodivergent. Angew. Chem., Int. Ed. 2013, 52, 13149. Selected examples: (f) Kim, B.; Kim, Y.; Lee, S. Y. Stereodivergent Carbon-Carbon Bond Formation between Iminium and Enolate Intermediates by Synergistic Organocatalysis. J. Am. Chem. Soc. 2021, 143, 73. (g) Liu, X.-J.; Jin, S.; Zhang, W.-Y.; Liu, Q.-Q.; Zheng, C.; You, S.-L. Sequence-Dependent Stereodivergent Allylic Alkylation/Fluorination of Acyclic Ketones. Angew. Chem., Int. Ed. 2020, 59, 2039. (h) Wang, J.; Zheng, S.; Rajkumar, S.; Xie, J.; Yu, N.; Peng, Q.; Yang, X. Chiral Phosphoric Acid-Catalyzed Stereodivergent Synthesis of Trisubstituted Allenes and Computational Mechanistic Studies, Nat. Commun. 2020, 11, 5527. (i) He, Z.-H.; Jiang, X.; Hartwig, J. F. Stereodivergent Construction of Tertiary Fluorides in Vicinal Stereogenic Pairs by Allylic Substitution with Iridium and Copper Catalysts. J. Am. Chem. Soc. 2019, 141, 13066. (j) Ding, R.; De los Santos, Z. A.; Wolf, C. Catalytic Asymmetric Mannich Reaction of $\alpha$-Fluoronitriles with Ketimines: Enantioselective and Diastereodivergent Construction of Vicinal Tetrasubstituted Stereocenters. ACS Catal. 2019, 9, 2169. (k)Wang, S.; Rodríguez-Escrich, C.; Fianchini, M.; Maseras, F.; Pericàs, M. A. Diastereodivergent Enantioselective [8+2] Annulation of Tropones and Enals Catalyzed by N-Heterocyclic Carbenes. Org. Lett 2019, 21, 3187. (I) Kwon, Y.; Chinn, A. J.; Kim, B.; Miller, S. J. Divergent Control of Point and Axial Stereogenicity: Catalytic Enantioselective C-N Bond - Forming Cross - Coupling and Catalyst - Controlled Atroposelective Cyclodehydration, Angew. Chem., Int. Ed. 2018, 57, 6251. (m) Huang, H.; Konda, S.; Zhao, J. C.-G. Diastereodivergent Catalysis Using Modularly Designed Organocatalysts: Synthesis of Both Cis- and Trans-Fused Pyrano[2,3-b]pyrans. Angew. Chem., Int. Ed. 2016, 55, 2213. (n) Krautwald, S.; Sarlah, D.; Schafroth, M. A.; Carreira, E. M. Enantio- and Diastereodivergent Dual Catalysis: $\alpha$-Allylation of Branched Aldehydes. Science 2013, 340, 1065.

(xii) No reaction occurred when the reaction was performed in $\mathrm{MeOH}$ as solvent.

( ${ }^{\text {xiii) }}$ Reaction performed best in presence of MS, but is also very effective in its absence (Table 1, entry 5). Reaction was also effective in presence of 5 equivalent of $\mathrm{H} 2 \mathrm{O}$ (see supporting information, Scheme S2).

( ${ }^{\mathrm{xiv}}$ ) García-García, C.; Ortiz-Rojano, L.; Álvarez, S.; Álvarez, R.; Ribagorda, M.; Carreño, M. C. Friedel-Crafts Alkylation of Indoles with p-Quinols: The Role of Hydrogen Bonding of Water for the Desymmetrization of the Cyclohexadienone System. Org. Lett. 2016, 18, 2224.

${ }^{(\mathrm{xv})}$ Of note, the cationic part of $\mathrm{E}$ has a trans configuration with respect to the exocyclic $\mathrm{C}=\mathrm{C}$ bond. The cis isomer is less stable by $2.1 \mathrm{kcal} / \mathrm{mol}$. ${ }^{\left({ }^{\mathrm{xi}}\right)}$ Tertiary-dienecarbamates were tested in the reaction (See the Supporting Information, Scheme S1) and no product was formed presumably due to their lower reactivity compared to the secondary counterparts. For diminished nucleophilicity of tertiary enamides, See ref 8 e and $8 f$ 